\title{
USINAS ESCURAS $x$ LOCUS AMOENUS (A estética da mercadoria em $O$ açúcar, de Ferreira Gullar)
}

\author{
Hermenegildo José Bastos (UnB)
}

A obra literária é regida por suas próprias leis, ou mais, ela traz em si as leis de sua legibilidade - dizer isso é hoje quase um lugar-comum. Mas a afirmação necessita de definição histórica: prescindir a obra literária de outras leis que não as suas só se coloca no horizonte da modernidade. É aí que se concebe e se pratica a literatura como reino autônomo, como um discurso que tudo pode dizer e independentemente das prescrições morais e religiosas do mundo pré-moderno. Já não há então outras leis a observar, senão a dessa autonomia. Prescindindo de outras leis, externas a ela, a literatura se firma como um reino ao mesmo tempo autônomo e desgarrado. Em vão procurar-se-á alguma coisa que the dê sustentação.

O caráter moderno da literatura se encontra nessa recusa à lei não-literária. É a ilusão da liberdade burguesa, mas, como ilusão, é uma verdade histórica. Então, ao mesmo tempo que se liberta do que the é alheio, a literatura se preserva um valor de distinção ante o que é do mundo do trabalho vil - o artesanato. A delimitação dessa distinção está feita na própria obra. Não basta que ela se distinga fora, nos rituais da comunicação literária, ou melhor, esses rituais somente serão cumpridos se se encontrarem dispostos na materialidade do texto. Esse deve ter os botões que acionam a leitura literária e reproduzem a distinção.

Para se distinguir do artesanato, que é trabalho e produção, a arte literária, paradoxalmente, se dá como uma engrenagem cujos dispositivos de funcionamento, não estando fora dela - uma vez que ela se pensa autônoma -, vêm internalizados. Com isso, contudo, evidencia (c essa é a primeira informação estética) o seu caráter poético, isto é. de produção. Ora, que a obra é produção (no sentido mesmo da palavra poesia) é uma afirmação bastante antiga, mas não tão pacífica se considerarmos as suas implicações histórico-sociais. A obra inclui as leis de sua própria elaboração, mas, além disso, exibe-as. Por que e para 
quê? A exibição, e, nela, o que há de exibição da má-consciência do sujeito poético, é que nos interessa aqui.

A exibição é uma forma de autopropaganda. Exibindo os seus dotes (sua autonomia), a obra apregoa os valores da própria literatura. Mas o texto que se exibe e, dessa forma, se encarece, evidencia, ao mesmo tempo, suas contradições.

A obra literária carrega em todas as suas letras as marcas do trabalho despendido na sua produção. Algumas vezes, a voz narrativa ou a voz lírica comenta ou mesmo reclama do custo de produção da obra, encarecendo-a. Outras vezes, nada se diz explicitamente. Porém toda linha, toda construção, toda seleção vocabular e toda combinação são o produto, mas também os vestígios da produção. Do leitor é cobrado também um trabalho - o de perceber o dispêndio, avaliá-lo, comprometer-se com ele. Por isso dizemos que a obra literária não se dá gratuitamente, posto que se encarece. Tem custo e tem preço. Cada passagem traz internalizada o quanto foi despendido na sua construção. Isso tem um peso particular: as marcas internalizadas do custo literário são metonímias das relações de trabalho vigentes no momento da produção da obra. Ela revela a força de trabalho literária nela investida e, por esse viés, revela as relações de trabalho dominantes da sua época. Cada traço (sua escolha, sua pertinência, seu valor) é elemento de uma tessitura maior que a da obra. Literatura é, portanto, um certo tipo de trabalho. Um tipo especial. Essa é a primeira informação estética que a obra nos dá (leiam-me e entendamme segundo as minhas próprias determinações), uma informação sobre a própria obra, sobre o seu caráter especial e distinto, sua diferenciação. O paradoxo está em que a condição mesma da autonomia é um dado histórico, extraliterário: a obra literária atende apenas às suas próprias leis porque essa é uma lei da modernidade e do desenvolvimento do capitalismo de que a literatura é parte constitutiva.

\section{II}

N'O açúcar, de Ferreira Gullar, a voz lírica é a de um escritor-personagem dilacerado pela consciência de que o seu poema não só não pode escapar do universo da forma-mercadoria, como, mais do que isso, brota na verdade do seu solo. O alto refinamento artístico (o açúcar ou o doce de que fala o poema) é o último estágio de refinamento da produção capitalista. Assim colocado, nos termos 
da homologia entre o modo de produção econômica e o modo de produção literária, qual o sentido do fazer poético? Que não se encontra no ideal da aurea mediocritas parece claro: o mundo reconciliado pelos deuses já não está disponivel, não há paz à vista.

"O açúcar" é um poema de Dentro da noite veloz. Ei-lo:

O branco açúcar que adoçará meu café nesta manhã de Ipanema não foi produzido por mim nem surgiu dentro do açucareiro por milagre.

Vejo-o puro

E afável ao paladar

Como beijo de moça, água

$\mathrm{Na}$ pele, flor

Que se dissolve na boca. Mas este açúcar

Não foi feito por mim.

Este açúcar veio

Da mercearia da esquina e tampouco o fez o Oliveira,

Dono da mercearia.

Este açúcar veio

De uma usina de açúcar em Pernambuco

Ou no Estado do Rio

E tampouco o fez o dono da usina.

Este açúcar era cana

E veio dos canaviais extensos

Que não nascem por acaso

No regaço do vale. 
Em lugares distantes, onde não há hospital

Nem escola,

Homens que não sabem ler e morrem de fome

Aos 27 anos

Plantaram e colheram a cana

Que viraria açúcar.

Em usinas escuras,

Homens de vida amarga

E dura

Produziram este açúcar

Branco e puro

Com que adoço meu café esta manhã em Ipanema. '

O poema lírico gira em torno do eu. Os acontecimentos narrados são vividos e filtrados pelo eu, e é assim que o texto se impõe ao leitor. Não é uma narrativa de acontecimentos, mas a expressão dos efeitos desses acontecimentos na subjetividade do poeta. Contudo, o poema vai se mover em direção ao mundo dando a ver uma condição problemática do eu. Diz o poeta que o café a ser adoçado é 'meu', a manhã de Ipanema, qualificada como 'esta', é também a sua. O açúcar, por sua vez, é branco, o que deve ser entendido como 'purificado', ou mesmo, 'puro'. Entretanto, o açúcar "não foi produzido por mim". Ser produzido contrapõe-se a existir por milagre. Como se verá, este contraponto tem grande importância também para o poema, cuja existência hesita entre ser milagre e produção. A situação vivida pelo eu aproxima-se do ideal de otium cum dignitate, mas inclui um elemento contrário que contamina o eu e o condena ao dilaceramento.

O eu tenta recuperar, nos 33 versos do poema, o processo de produção do açúcar, como numa história contada de trás pra frente, em que os últimos acontecimentos precedem os primeiros. Como numa desmontagem, o açúcar percorre o caminho de volta do açucareiro para a mercearia do Oliveira, daí para a usina em Pernambuco ou no

Gullar, Ferreira. Toda poesia (1950-1980). 1980, p. 227-8. 
Estado do Rio, até chegar aos canaviais que "não nascem por acaso/ no regaço do vale". Por fim chega aos homens que o plantaram e o colheram.

Não é uma narrativa pura e simplesmente, mas uma narrativa confessional. O eu transmite-nos sua culpa: até chegar à sua mesa, na sua manhã, e adoçar o seu café, o açúcar passa por várias transformações, dir-se-iam mágicas ou milagrosas, no sentido de que cada passo do trajeto das "usinas escuras" até o açucareiro esconde o passo anterior. O branco do açúcar que vem das "usinas escuras" é resultado de uma escamoteação. A produção não se dá sem a sua própria escamoteação. Na sucessão das etapas da produção, alguma coisa é desprezada, deixada para trás, jogada fora como bagaço. $\mathrm{O}$ açúcar é branco, sem máculas, purificado, refinado. O refinamento é o processo de escamoteação da exploração de quem plantou e colheu.

Na sua condição, traduzida pela manhã em Ipanema e pelo café a ser adoçado, que são seus, o poeta se sente cúmplice do processo de escamoteação. O que está em jogo, portanto, é, mais do que a produção do açúcar, a produção do poema, ou melhor, a íntima relação entre as duas produções. O refinamento é, então, tanto do açúcar quanto do poema. Ligando os dois, está o fato de que, na sucessão das etapas da produção, alguma coisa é desprezada, deixada pra trás como bagaço. Na verdade, o que adoça a manhã em Ipanema é o doce do poema, que, por sua vez, é a quintessência do doce do açúcar.

A manhã em Ipanema é um locus amoenus, ao qual se contrapõem as "usinas escuras". O locus amoenus seria o lugar do milagre; as "usinas escuras", o da produção. Mas, como o poema é também produzido - e é isso que o poeta sublinha, enfatiza - , então o milagre é o suplemento ideológico de escamoteação de tudo o que está envolvido no processo de produção.

O poema, como o açúcar, é "afável ao paladar/ como beijo de moça, água/ na pcle, flor/ que se dissolve na boca". É o refinamento dos refinamentos. Mas se o poeta não fez o açúcar, ao menos faz o poema?

As produções do açúcar e do poema obedecem a esquemas modernos, perfazem o longo caminho da industrialização, com as inúmeras transformações pelas quais passa a matéria-prima submetida 
ao valor de troca, à forma-mercadoria. O consumo - leitura, no caso do poema - não pode se consumar sem o ilusionismo ou a fantasmagoria das metamorfoses.

O açúcar da arte adoça a manhã do poeta e de seus leitores. A arte é, pois, o refinamento do refinamento, o estágio mais avançado ("na pele, flor") da produção capitalista, a transformação mais sutil e fantasmagórica. Ao dizer que o açúcar não foi feito por ele, o poeta nos diz que o poema também não é um milagre, embora se oferte como tal; diz-nos que a matéria do poema que ele faz na manhã de Ipanema é a produção do açúcar e que, sendo assim, vem lá também das "usinas escuras". A matéria do poema é a vida amarga dos "homens de vida amarga". A matéria-prima do poema - o açúcar posto no café - já vem produzida. Por isso. enquanto o poeta acompanha o processo de desmontagem do açúcar e recupera, passo a passo, as etapas de sua produção, o leitor acompanha a produção do poema enquanto ela se dá. Observe-se que acima, a propósito da feitura do poema, eu disse faz, não fez. O leitor é levado a refazer retrospectivamente os passos da produção do açúcar, mas a acompanhar o poeta no momento mesmo em que ele faz o poema. Talvez aqui esteja um dado a ser investigado.

A diferença está em que o poema começa quando o açúcar já está feito e disponivel no açucareiro. Ao leitor resta envolver-se na história, entrar no fogo cruzado. O que é dado como bagaço, pela produção do açúcar, é o indigesto do poema ou o poema indigesto, não comestivel, amargo, que o leitor deve compartilhar.

A culpa do poeta está em que fazer o poema é participar do longo processo de escamoteação, uma vez que o poema, que também é produzido, é a última etapa da produção de bens de consumo. O poema integra o processo de produção da mercadoria e. mais do que isso, também se dá como mercadoria e, ainda mais, fazendo-se passar por resultado de um milagre, é o refinamento do refinamento da escamoteação: o fetiche. Poderá o leitor resgatá-lo enquanto elemento indócil, não submetido a todo esse processo?

Dentro da noite veloz, livro em que se publicou "O açúcar", marca, segundo mostra Lafetá, uma fase de mudança na poesia de Ferreira Gullar: diferentemente do que ocorreu nos livros anteriores, agora as posições políticas vão surgır "não mais como algo de fora(...), mas como algo interior, da vida do poeta, e do qual se fala" 
(1982, p. 62). Como Lafetá também demonstrou a propósito de Poema sujo (1983), a subjetivização permite ao poeta superar os problemas iniciais da sua poesia (esteticismo, formalismo à geração de 45), mas ao mesmo tempo funciona como um limite. N' "O açúcar" o limite se deixa ver e, mais do que isso, deixa ver o dilaceramento do poeta: colocado, como escritor, do lado de cá da fronteira, ele pode contar a vida dos "homens de vida amarga", mas na posição de quem, ainda que contra sua vontade, se beneficia dela.

Em outros momentos da poesia brasileira, como observa ainda Lafetá, os poetas puderam atingir maior veemência do que se vê nesses textos. Lafetá cita $O$ carro da miséria de Mário de Andrade, $A$ Rosa do povo de Drummond como exemplos dessa veemência. Mesmo assim, pôde-se verificar um retrocesso quando as "conquistas" modernistas cederam lugar ao esteticismo da geração de 45 . Se isso ocorreu é porque alguma fragilidade do próprio modernismo forneceu a brecha por onde isso se deu. Lembre-se de que os "grandes" do modernismo, já pelos meados dos anos 40 e depois nos anos 50, renegavam aquelas "conquistas". Foram eles mesmos que voltaram aos sonetos, ao requinte poético, à linguagem rebuscada e, outra vez, distante da fala popular e coloquial. Pode-se então supor que, sem poder ir à frente no sentido da radicalização daqueles procedimentos, o modernismo deparou-se com o seu próprio limite. Disse Lafetá que Gullar "operou nos limites da consciência do artista (intelectual) brasileiro contemporâneo, preocupado com os problemas sociais do seu país" $(1983,200)$. Os limites não foram rompidos. Supõe Lafetá que talvez porque "a nossa "consciência possível" de intelectuais esbarre no círculo-de-ferro de nossa classe, e o "outro" - representado obliquamente através de suas refrações no sujeito poético - não ganhe nas obras a autonomia e a força capazes de colocá-lo no centro do processo".

O limite é na verdade a própria literatura, e a explicitação disso n' "O açúcar" talvez possa ser considerada uma forma nova de veemência com que a poesia anterior não contava. Ao falar do eu e sua subjetividade, o poema fala da condição mesma de existência do fenômeno lírico numa sociedade de classes. Não há como discordar de Lafetá: os limites não foram superados. Releia-se o bloco final do poema: 
Em usinas escuras,

Homens de vida amarga

E dura

Produziram este açúcar

Branco e puro

Com que adoço meu café esta manhã em Ipanema.

O tom é de derrota e, até mesmo, elegíaco, mesmo porque informar sobre a existência desses homens nada acrescenta ao que a literatura brasileira já vem fazendo há algum tempo. O que é relevante, porém, é que se expõe o comprometimento do fazer literário.

Se, como diz Lafetá, a subjetivização foi o caminho de superação do esteticismo inicial da poesia de Gullar, feito isto, ela se colocou, entretanto, como o novo limite e, dessa vez, intransponível: o "círculo de ferro de nossa classe", barreira para a representação do "outro". O sujeito poético é, ao mesmo tempo, individual e coletivo, como tal, integra um horizonte histórico. Os limites desse horizonte, portanto, não são da poesia de Ferreira Gullar, mas da poesia brasileira. O mal-estar que essa poesia pode causar no leitor prevenido está em que ela beira a autopiedade.

A autopiedade poderá ser tomada como categoria históricoliterária? Se for, será um dado estilístico-ideológico e não uma acusação dirigida a este ou aquele escritor. Lembre-se como isso percorre a poesia de língua portuguesa moderna: "E estou-me rebolando numa grande caridade por mim", diz Fernando Pessoa. Afinal "Sim, eu sou também vadio e pedinte/ E sou-o também por minha culpa" (1969, p. 414).

Ao falar de subjetivização, pensamos em um processo, ao invés de num dado pacífico e preexistente ao texto. A subjetividade está no texto como resultado de um processo propriamente literário que corresponde aos processos ideológicos de interpelação do indivíduo em sujeito. Um conjunto de mecanismos morfossintáticos, semànticos e retóricos produzem o sujeito. Este que no texto diz eu nào é, portanto, o ponto de partida do texto, mas o seu ponto de chegada. O ilusionismo está em que o poema se apresenta como produto do eu, quando na verdade o produz. 
O leitor, acompanhando a produção d' "O açúcar", tem a rara oportunidade de ver a fabricação da ilusão. Nesse sentido, o poema caminha em duas direções opostas, mas ao final convergentes: a $1^{\text {at }}$ é

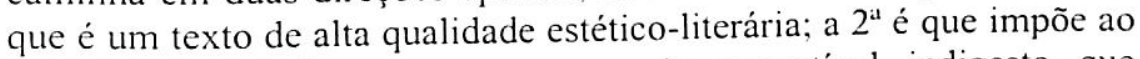
leitor o amargo do poema, o poema não-comestivel, indigesto, que implica um questionamento dessa alta qualidade estético-literária. $\mathrm{O}$ leitor pode ficar com o poema altamente bem realizado, mas cuja excelente qualidade estético-literária é parte do universo da produção capitalista, ou ficar com a sua autocrítica. Em ambos os casos, porém, terá que digerir um impasse.

\section{II}

Tomar em termos literários (e não psicológicos, sociológicos) a subjetividade do autor significa trazer à tona as questões que a literatura coloca para si mesma evidenciando uma autocrítica tanto da literatura quanto daquele que a pratica. A literatura que se autorepresenta pergunta pelo significado de haver literatura, pelo papel e função da obra literária na vida social enquanto forma especial de comunicação. Trata-se, então, de assinalar, nos elementos estruturais da narrativa e da poesia, os momentos de autoconsciência do escritor, que, convertido em narrador ou personagem, reflete sobre (ou simplesmente experimenta) o papel da escrita e do escritor na sociedade, as suas contradições e conflitos. São questões concernentes à forma literária, ou melhor, são, como questões, aquilo mesmo que define a qualidade diferencial do literário. Em outras palavras, o diferencial literário é já uma questão, jamais pode ser visto como uma coisa pacífica, estabelecida de uma vez para sempre. O leitor e o crítico, por sua vez, convertidos em leitor implícito, são partes de uma trama social em que a literatura tem papel proeminente.

A obra literária tem, assim, em tese, uma força de transgressão: é o momento em que a linguagem se confronta consigo mesma e, como tal, desfaz o aparente equilibrio em que se sustenta a vida social e suas máscaras. A obra literária revela um sujeito cindido, não constitutivo de qualquer sentido, mas constituido como função narrativa. Logo, a expressão 'autoconsciência do escritor' não deve nos enganar. Em princípio designa esse momento em que a linguagem se choca contra os seus próprios limites. Mas aqui também vale um reparo: se a linguagem é a consciência imediata do homem, então, quando ela se choca com os seus próprios limites, é a sociedade que se 
projeta em um espelho. O espelho não devolverá uma imagem fidedigna, uma vez que sempre será ideológica, mas, no decorrer da história, a imagem corresponderá a uma nova projeção da sociedade e a uma atualização do estado dos conflitos.

O sujeito é produto do poema, não o seu produtor. O poema é, assim, uma prática discursiva ideológica. O sujeito da enunciação tampouco escapa dessas amarras, mas, ao se mover no espaço do poema, espaço rigorosamente fechado, tenta forçar as suas barreiras e escancarar o comprometimento da literatura. É assim que o poema pode ser um espaço aberto por dentro do espaço fechado. Não é jogo de palavras. A condição da abertura (tomada aqui como recusa das imposições da instituição literária) é a consciência da instituição.

"O açúcar" é, assim, uma ars poetica. Se aí se questiona o milagre do poema, não será, porém, para enfatizar a sua total dependência da forma-mercadoria. Até aí, permanecemos no universo da autopiedade, sem saída possível. Ressalve-se que a autopiedade pode gerar e tem gerado obras de primeiro escalão. Mas o desejo que enforma "O açúcar", a sua veemência, pode funcionar como uma bomba a explodir no interior do poema, fazendo os açúcares e os doces desandarem.

\section{REFERÊNCIAS BIBLIOGRÁFICAS}

GULLAR, Ferreira. Toda poesia (1950-1980). Rio de Janeiro: Civilização Brasileira, 1980.

L.AFETÁ, João Luiz. Traduzir-se (Ensaio sobre a poesia de Ferreira Gullar). O nacional e o popular na cultura hrasileira São Paulo:
Brasiliense, 1982 .

LAFETÁ, João Luiz. Dois pobres, duas medidas. In: SCHWARZ, Roberto (org.). Os pobres na literatura brasileira. São Paulo: Brasiliense, 1983.

PESSOA, Fernando. Obra poética. Rio de Janeiro: Companhia José Aguilar Editora, 1969.

S(HWARZ, Roberto (org.). Os pobres na literatura brasileira. São Paulo: Brasiliense, 1983. 